\title{
A TRILHA DO PEITO DO POMBO E O PERFIL DOS VISITANTES NA ÁREA DE PROTEÇÃO AMBIENTAL (APA) DO SANA - MACAÉ/RJ
}

Adriano Oliveira da Silva ${ }^{1}$

\section{RESUMO}

Luiz Renato Vallejo ${ }^{2}$

As áreas protegidas contribuem para a proteção dos recursos naturais, proporcionarem o uso público através de atividades turísticas, recreativas, educativas, entre outras. O conhecimento prévio e o planejamento de uso dessas áreas são essenciais para sua conservação, principalmente no tocante ao estado das trilhas. O presente artigo apresenta informações sobre a Trilha do Peito do Pombo na Área de Proteção Ambiental do Sana (Macaé/RJ), seus usos e um levantamento geral sobre as características socioeconômicas de 98 usuários que foram entrevistados num período de intensa procura dos atrativos locais, principalmente os banhos de rio e cachoeiras. A extensão total da trilha é de $15 \mathrm{~km}$ (ida e volta) e este estudo foi realizado num trecho de 1,330 $\mathrm{km}$, onde ocorre intensa circulação de usuários que buscam as piscinas naturais, principalmente nos meses mais quentes do ano (primavera e verão). Existem problemas de compactação e erosão do solo e poucas iniciativas voltadas à segurança dos usuários. A área atrai pessoas de várias regiões do Rio de Janeiro e também de outros estados. Muitos se hospedam no local, mas um percentual considerável permanece na área por um período inferior a 24 horas. Existem carências na fiscalização e nas estruturas de manejo que afetam negativamente as condições da trilha, assim como o princípio básico de manutenção de uma área protegida. Os dados obtidos poderão subsidiar iniciativas que melhorem a conservação e manejo da área, principalmente na segurança dos usuários.

Palavras-chave: Unidade de conservação; uso público; trilha

\section{“PEITO DO POMBO" TRAIL AND THE PROFILE OF VISITORS IN SANA ENVIRONMENTAL PROTECTION AREA (MACAÉ / RJ)}

\section{ABSTRACT}

Protected areas contribute to the protection of natural resources, provide public use through tourism, recreational, educational activities, among others. Previous knowledge and planning of use of these areas are essential for their conservation, especially regarding the state of the trails. This article presents information about the "Peito do Pombo" Trail in the Environmental Protection Area of Sana (Macaé/RJ), its uses and a general survey about the socioeconomic characteristics of 98 users who were interviewed during a period of intense search for local attractions, especially the baths river and waterfalls. The total length of the trail is $15 \mathrm{~km}$ (round trip) and this study was carried out in a stretch of $1,330 \mathrm{~km}$, where there is intense circulation of users looking for natural pools, especially in the hottest months of the year (spring and summer). There are problems of compaction and soil erosion and few initiatives aimed at user safety. The area attracts people from various regions of Rio de Janeiro and also from other states. Many

\footnotetext{
${ }^{1}$ Graduado em Geografia, Universidade Federal Fluminense. E-mail: adrianoos.geo@gmail.com

${ }^{2}$ Prof. Titular do Programa de Pós Graduação em Geografia/UFF. E-mail: luizrenato@id.uff.bfr
} 
people stay on site but a considerable percentage remains in the area for less than 24 hour. There are deficiencies in monitoring and management structures that adversely affect trail conditions, as well as the basic principle of maintaining a protected area. The obtained data will be able to subsidize initiatives that improve the conservation and management of the area, mainly in the safety of users.

Keywords: Protected area; public use; trail

\section{INTRODUÇÃO}

No Brasil, O Sistema Nacional de Unidades de Conservação da Natureza (SNUC), instituído pela Lei n ${ }^{\circ} 9.985$ de 18 de Julho de 2000, estabeleceu critérios e normas para a criação, implantação e gestão das Unidades de Conservação (UC). Esta Lei proporcionou avanços na definição das classificações e dos objetivos de manejo das áreas protegidas. O SNUC divide as UC em dois grupos: Proteção Integral e Uso Sustentável. Em algumas UC são desenvolvidas atividades de uso público, como recreação, práticas educativas, de lazer entre outras. O termo uso público é definido como o processo de visitação das áreas protegidas, podendo se manifestar como atividades educativas, de lazer, esportivas, recreativas, científicas e de interpretação ambiental, que proporcionam ao visitante a oportunidade de conhecer, entender e valorizar os recursos naturais e culturais existentes (MINISTÉRIO DO MEIO AMBIENTE, 2005). Entretanto, se as atividades não forem planejadas respeitando as vulnerabilidades e as potencialidades da área visitada, pode-se comprometer o estado de conservação das mesmas.

A trilha do Peito do Pombo, objeto do presente estudo, localiza-se no distrito do Sana, situado na porção serrana do município de Macaé, estado do Rio de Janeiro. Os limites do distrito correspondem aos da Área de Proteção Ambiental (APA) do Sana, UC de uso sustentável criada em 2001 pela Lei Municipal 2.172.

A referida trilha é o principal acesso para se chegar aos locais onde são praticadas diversas atividades como banho de rio, caminhadas, etc. Segundo Gaspar (2003), as atividades turísticas no Sana tiveram início em meados dos anos de 1980, através de caminhadas em trilhas e outros usos. Esta prática pode trazer inúmeros impactos ambientais devido ao grande número de pessoas que buscam maior contato com natureza. Há um grande número de trabalhos sobre trilhas, tanto no Brasil, quanto em outros países. Destacam-se na literatura brasileira os trabalhos de Takahashi (1998); Magro (1999); Costa (2006); Melo (2008); Kroeff (2010); Andrade et al (2010); Cova et al (2013); Rangel et al (2013); Silva et al (2015); Rangel e Botelho (2017), dentre outros.

\section{MATERIAL E MÉTODOS}

Foram realizados pesquisas bibliográficas e trabalhos de campo com o objetivo de descrever, caracterizar, observar e registrar fotograficamente os aspectos da trilha, além da situação do piso, obstáculos naturais e impactos humanos, entre outros. Nos dias 02 e 03 de novembro de 2018, foram aplicados 98 questionários aos visitantes com 14 questões, sendo 11 fechadas e 3 abertas (semi-estruturado). Segundo Labes (1998), as questões fechadas facilitam o 
preenchimento do questionário, são fáceis de codificar e tabular e auxiliam na compreensão da pergunta. As perguntas formuladas abrangeram inicialmente dados socioeconômicos como: sexo, idade, renda, escolaridade, cidade de origem, entre outros. Também foram solicitadas informações sobre os interesses do visitante, sua percepção sobre a importância da preservação da área onde está inserida a trilha e obter sugestões para melhorar a visitação. Segundo Gil (1989) este tipo de questionário tem como objetivo o conhecimento de opiniões, crenças, sentimentos, interesses, expectativas, entre outras.

A aplicação do questionário teve caráter quali-quantitativo, sem a preocupação de avaliar sua representatividade diante do universo de visitantes. O foco principal residiu na análise e a interpretação das experiências dos usuários da trilha, buscando subsídios para definir a melhor forma de manejo e garantir a satisfação e segurança do visitante. O próprio entrevistado se encarregou do preenchimento, sem a influência direta do pesquisador. Não houve uma preocupação com a padronização na aplicação, ou seja, alguns visitantes preencheram antes de percorrer a trilha, pois muitos já a conheciam, e outros responderam após o percurso, ou seja, retornando para seus lugares de origem.

Os dados coletados por meio dos questionários foram digitados e organizados no programa Excel, em planilha desenvolvida especificamente para este estudo. Para viabilizar o trabalho de campo, foi necessário contatar os funcionários da Secretaria Municipal de Meio Ambiente de Macaé e os proprietários das terras onde a trilha está inserida.

\section{RESULTADOS}

\section{1) Caracterização da área de estudo e seu entorno}

O distrito do Sana fica localizado na região serrana, município de Macaé, situado a 165 $\mathrm{km}$ da cidade do Rio de Janeiro (Figura 1). Faz limite com os municípios de Nova Friburgo (oeste) e Trajano de Morais (noroeste) e o principal acesso se dá pela RJ-142, na direção sul, que leva ao município de Casimiro de Abreu-RJ.

Até a década de 1940 prevaleceu a cultura do café como atividade econômica do distrito, sendo substituída pelas culturas do inhame, banana e mandioca, e pela criação de gado leiteiro. Com decadência do café muitos habitantes deixaram as localidades e os que permaneceram passaram a viver isolados, sem transporte coletivo e sem luz elétrica até 1986 (GASPAR, 2003). Este cenário teve mudanças a partir da segunda metade da década de 1980, quando o Sana começou a receber turistas em busca de suas belezas naturais, dentre outros atributos. Este novo quadro aqueceu a economia local, levando a construção de bares, campings, pensões, restaurantes, pousadas, bancas de artesões e algumas lojas.

Antes da chegada do turismo no Sana, alguns grupos adeptos ao "neo-ruralismo" j" já

\footnotetext{
${ }^{3}$ Em linhas gerais, o termo representa um conjunto de ideias e valores relacionados ao modo de vida no campo que são altamente desejados pelo povo da cidade. São pessoas que encaram o meio rural como um espaço de
} 
tinham se instalado na localidade desde os anos de 1970, fixando-se como comerciantes e contribuindo para as atividades e discussões de cunho ecológico, junto com os novos moradores de origem urbana (GASPAR, 2003). Em 30 de novembro de 2001, toda a extensão do distrito foi transformada em Área de Preservação Ambiental pela Lei Municipal n 2.172/2001.

Figura 1 - Localização da APA do Sana - Macaé/RJ

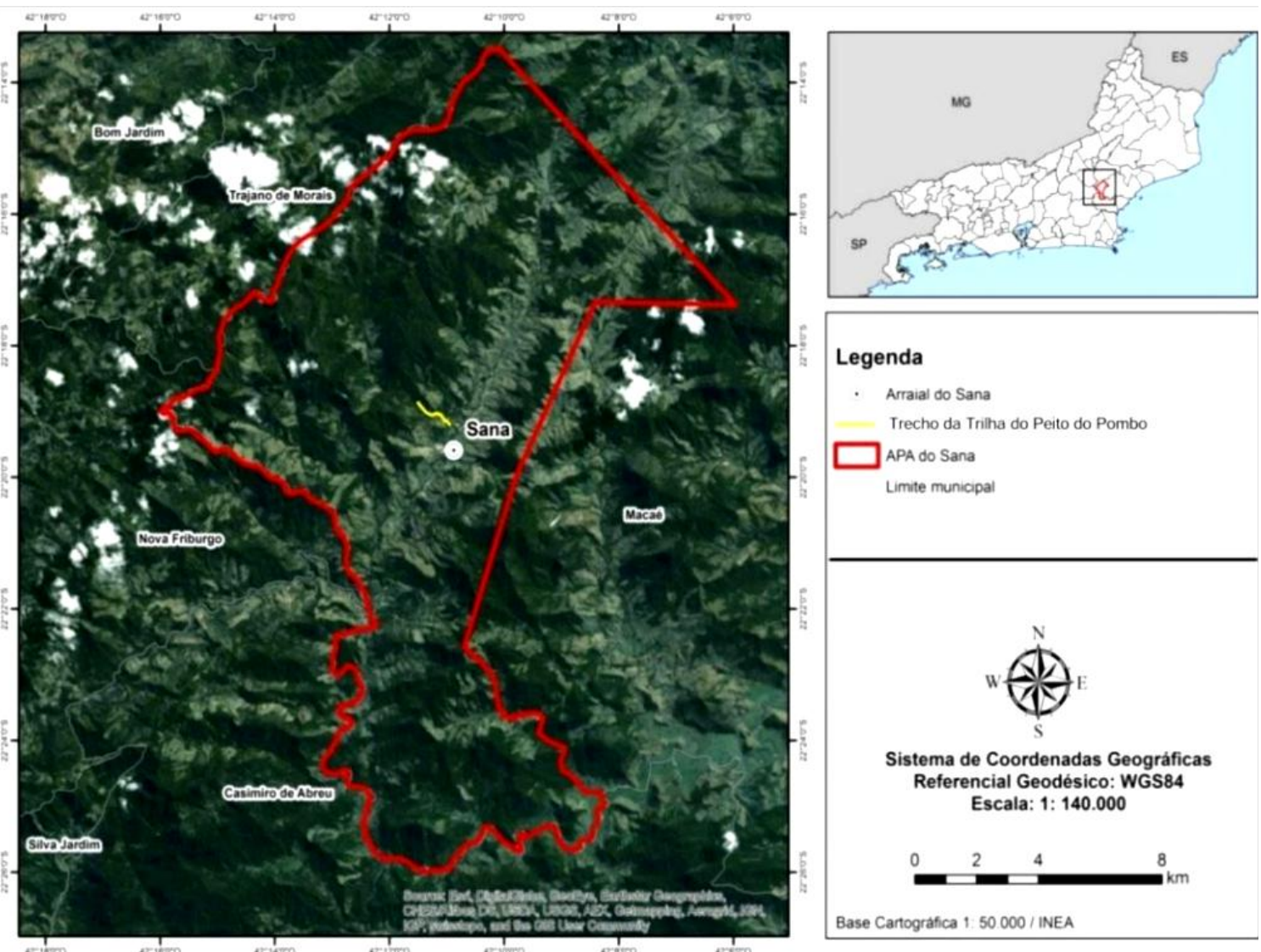

Fonte: Imagem do software Arcgis on line 2010. Elaboração: Adriano Oliveira (2018)

A área apresenta um relevo formado por planícies, colinas, morros e montanhas com encostas íngremes dissecadas por grotões úmidos, onde correm os rios e córregos. Sua topografia acidentada é formada por vales alongados, segmentos de drenagem retilíneos, linhas de cristas e cumeadas paralelas, relevo com grandes desníveis altimétricos e escarpas íngremes. A cota altimétrica do Sana varia de 190 metros a 1.800 metros (PMM, 2003).

A extensão total da Trilha do Peito do Pombo é de $15 \mathrm{~km}$ (ida e volta) iniciando-se no contato entre as colinas e serras escarpadas. Seu ponto culminante é Pedra do Peito do Pombo a 
$1.227 \mathrm{~m}$ de altitude (Figura 5A). Para os objetivos deste trabalho foram considerados apenas os $1.330 \mathrm{~m}$ iniciais onde a circulação dos usuários é mais intensa. Ela possui a maior parte da sua extensão em trechos montanhosos, num percurso de declividade acentuada e finalizando no contato entre os morros e serras locais, que variam de 200 a $400 \mathrm{~m}$ de altitude aproximadamente (Figura 2).

Figura 2 - Traçado da porção de 1330 m da Trilha do Peito do Pombo, APA do SANA.

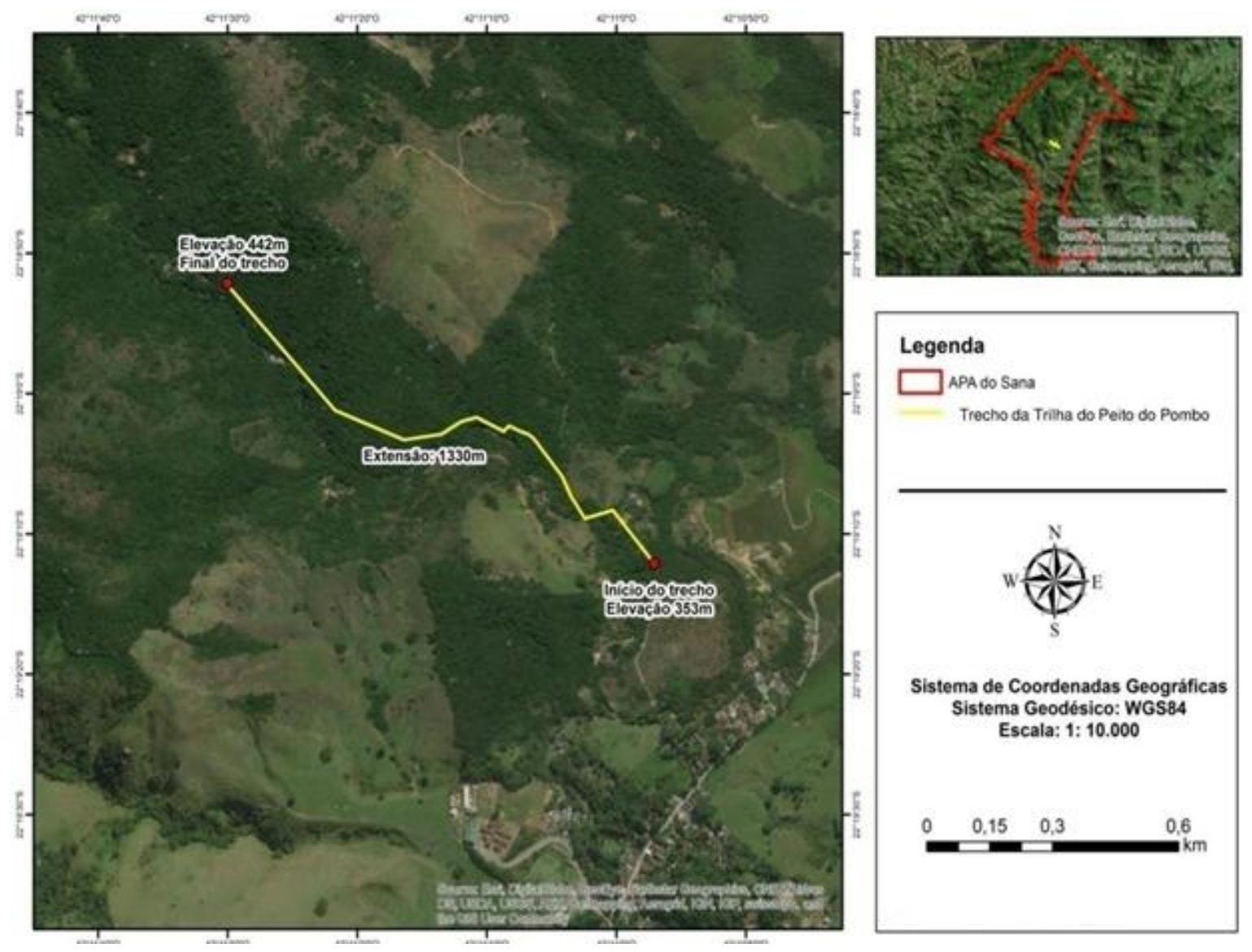

Fonte: Imagem do software Arcgis on line 2010. Elaboração: Adriano Oliveira (2018)

A região ainda detém remanescentes de floresta primária, embora predomine a vegetação secundária. A cobertura vegetal é tipicamente formada por mosaicos de vegetação constituídos por pastos, lavouras, fragmentos de florestas (primária e secundária), em diversos estágios de sucessão florestal (PMM, 2003). A trilha está inserida em grande parte da sua extensão na cobertura vegetal do tipo Floresta Ombrófila Densa Sub-Montana e termina no contato entre este e a Floresta Ombrófila Densa Montana, que prevalece como cobertura vegetal na APA. Os outros tipos aparecem de forma mais discreta na área da APA. 
O trecho estudado da Trilha do Peito do Pombo tem uma declividade média de 6,69\% numa extensão de $1.330 \mathrm{~m}$, com variação altimétrica de $89 \mathrm{~m}$, de curta distância, moderada e autoguiada, conforme critérios de Andrade (2003) e Instituto Florestal/SP (2008). Ocorre em relevo 'ondulado' e grau de dificuldade 'leve'. A trilha acompanha o córrego do Peito do Pombo na sua margem esquerda no sentido jusante à montante sendo utilizada para diversos fins (Figuras 3 A e B). Seu uso, somado aos fatores geoambientais (chuva, relevo, solo, cobertura vegetal), traz múltiplos impactos negativos que comprometem seu estado de conservação e até mesmo a segurança dos usuários (Figuras 4 A e B).

Figura 3 - A) Tráfego de animais (mulas e cavalos) e B) pisoteio dos caminhantes

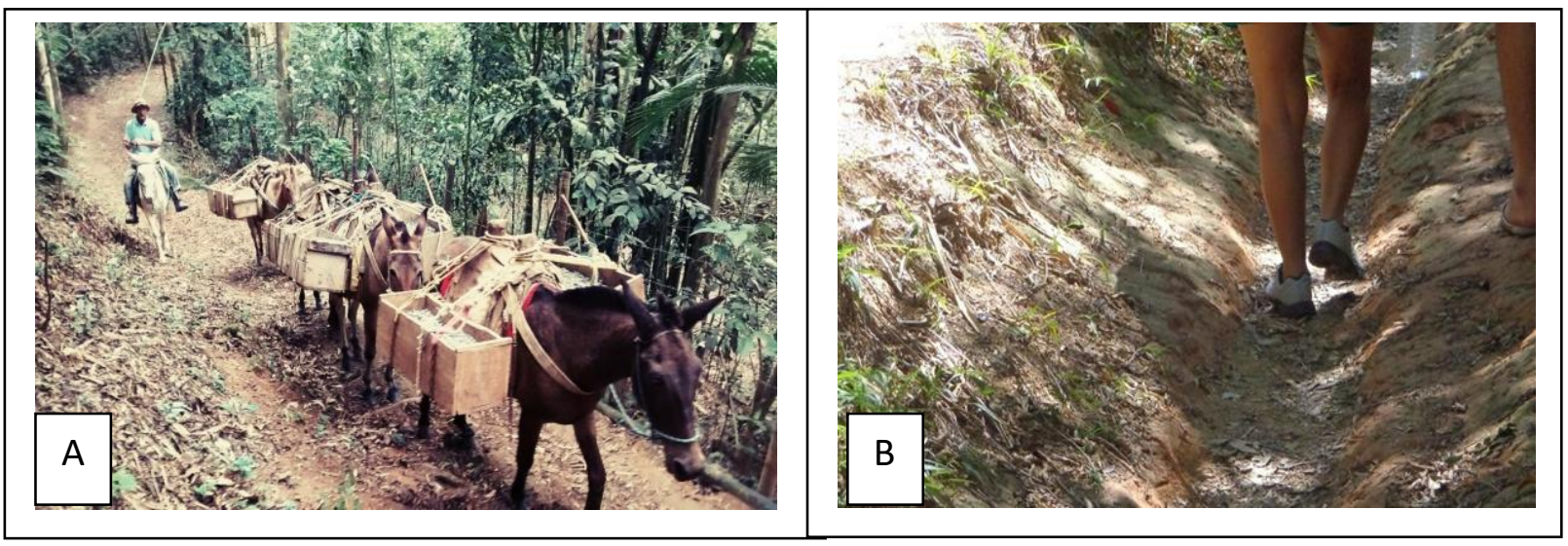

Fotos: Adriano Oliveira (2018)

Figura 4 - A) Piso com erosão e B) Raízes expostas na trilha

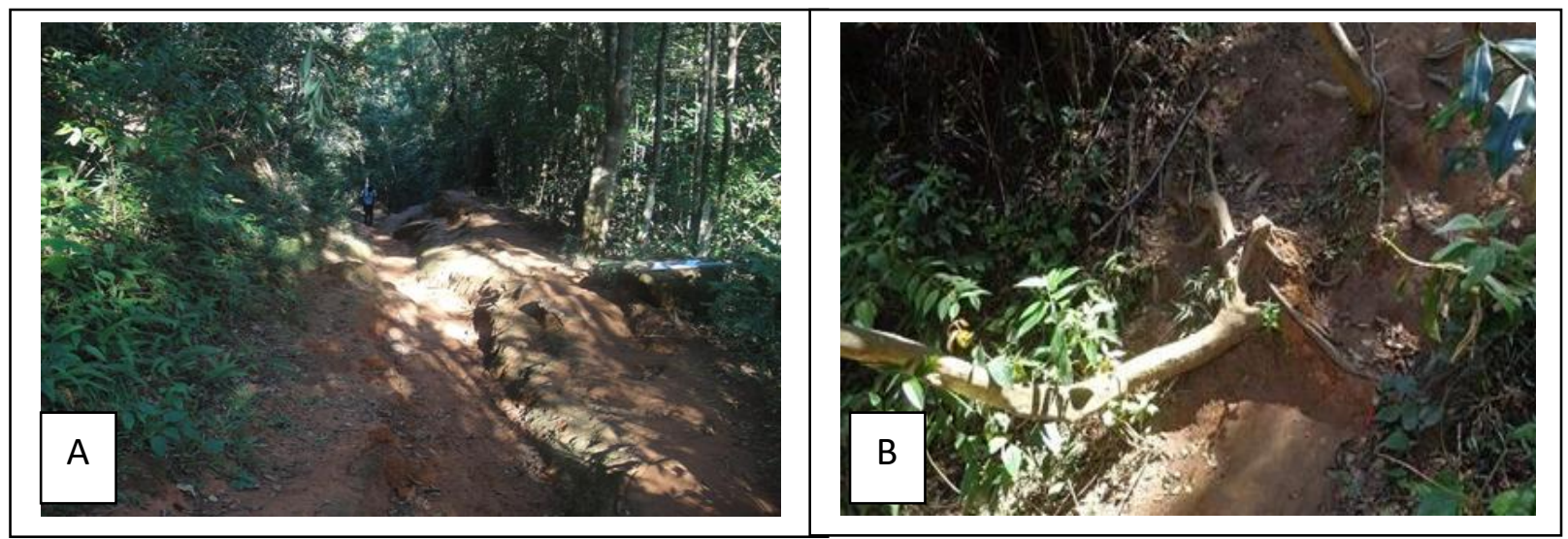

Fotos: A) Rosangela Botelho (2016) e B) Adriano Oliveira (2018)

A trilha principal conduz os visitantes ao pico do Peito do Pombo (Figura 5A), formação rochosa situada a $1.227 \mathrm{~m}$ de altitude e a $7,5 \mathrm{~km}$ do arraial do Sana (SEABRA, 2005). Antes do pico existem muitos pontos de banho (poços e cachoeiras), entre os quais destacamos: a) Poço do Escorrega: corresponde a um trecho do córrego de $20 \mathrm{~m}$ de largura e profundidade média de 1,40m. Suas pedras escorregadias fazem deste ponto o preferido dos visitantes; b) Cachoeira 
Mãe: um dos pontos mais exuberantes, onde há um poço com cerca de 3,50 $\mathrm{m}$ de largura e com uma profundidade de aproximadamente $2 \mathrm{~m}$; e c) Sete Quedas (Figura 5B): formação em degraus, de grande beleza cênica, utilizada como ducha por parte dos visitantes (SEABRA, 2005).

Figura 5 - A) Pico do Peito de Pombo e B) Cachoeira das Sete Quedas

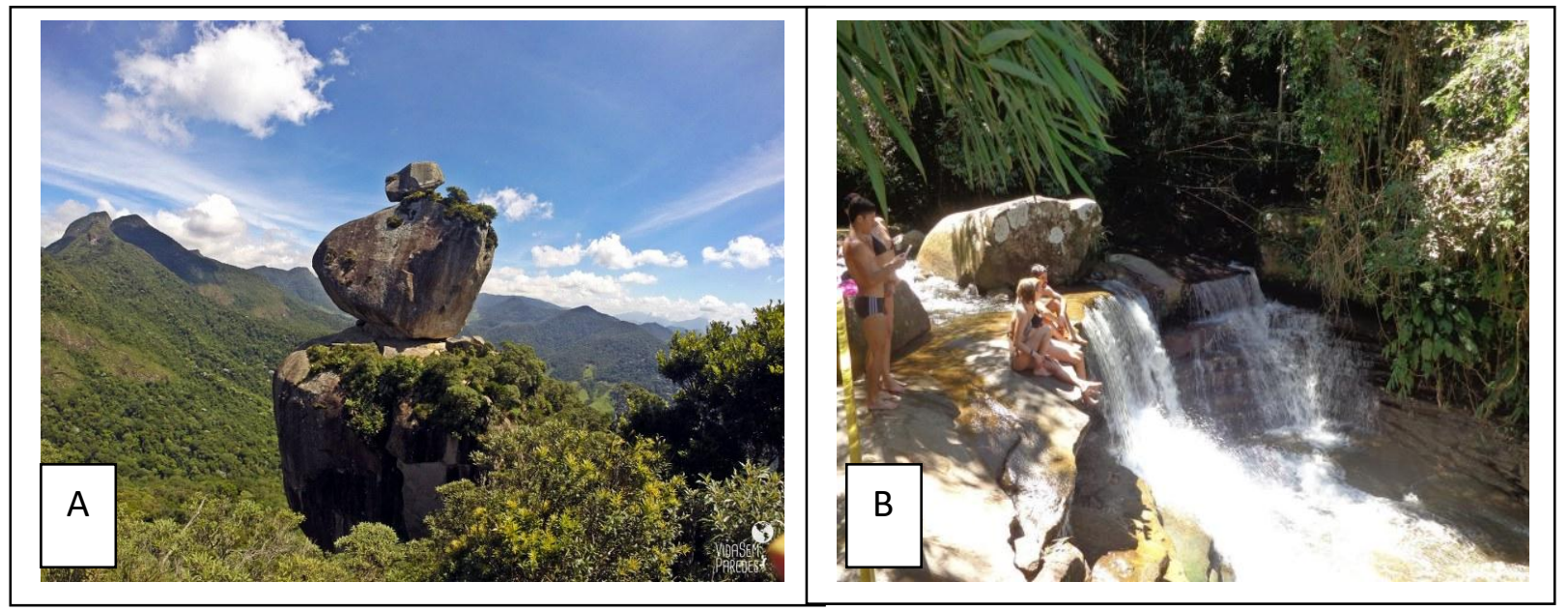

Fotos: A) https://pt.wikipedia.org/wiki/Pico_Peito_do_Pombo e B) Adriano Oliveira (2018)

\section{2) Perfil socioeconômico dos visitantes da Trilha do Peito do Pombo}

A amostragem identificou que a maior parte dos visitantes era do sexo feminino, ou seja 53 entrevistados $(54,0 \%)$, seguido pelos homens 42 (42,9\%) e mais 3 indivíduos $(3,1 \%)$ que não assinalaram o gênero. Prevaleceram pessoas com idades entre 21 e 30 anos $(59,2 \%)$, seguido pela faixa de 31 a 40 anos $(19,4 \%)$. A presença de jovens entre 10 e 20 anos teve $11,2 \%$, enquanto as demais faixas reuniram os 10,2\% restantes (Figura 6). Destacamos que a trilha não tem a infraestrutura adequada para receber pessoas muito idosas ou com deficiências físicas.

A Figura 7 mostra que a maioria dos visitantes entrevistados (48 pessoas $=49 \%$ ) possui graduação, seguida pelo ensino médio com 24 pessoas $(24,5 \%)$ e pós-graduação com 24 visitantes $(24,5 \%)$. Dessa forma, a amostra indicou um elevado nível escolaridade dos visitantes pesquisados.

Sobre a renda, predominaram pessoas na faixa entre 1 e 3 salários mínimos $(29,6 \%)$, seguidas de perto pelos que recebem entre 3 e $5(28,6 \%)$. Complementando, os que ganham mais de 5 salários abrangeram 26,3\% da amostra. Doze pessoas $(12,4 \%)$ declararam ganhar até 1 salário (Figura 8). 
Figura 6 - Faixa etária dos entrevistados

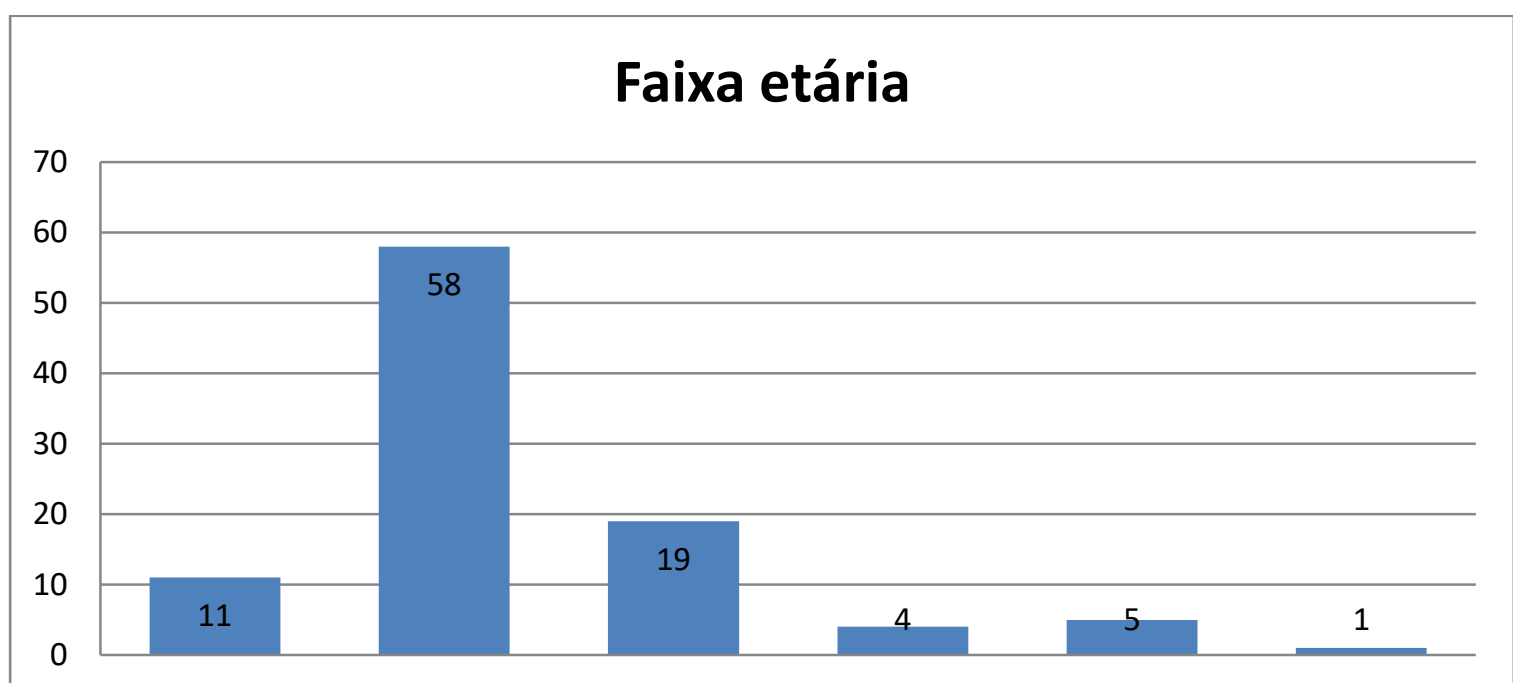

Figura 7 - Grau de instrução

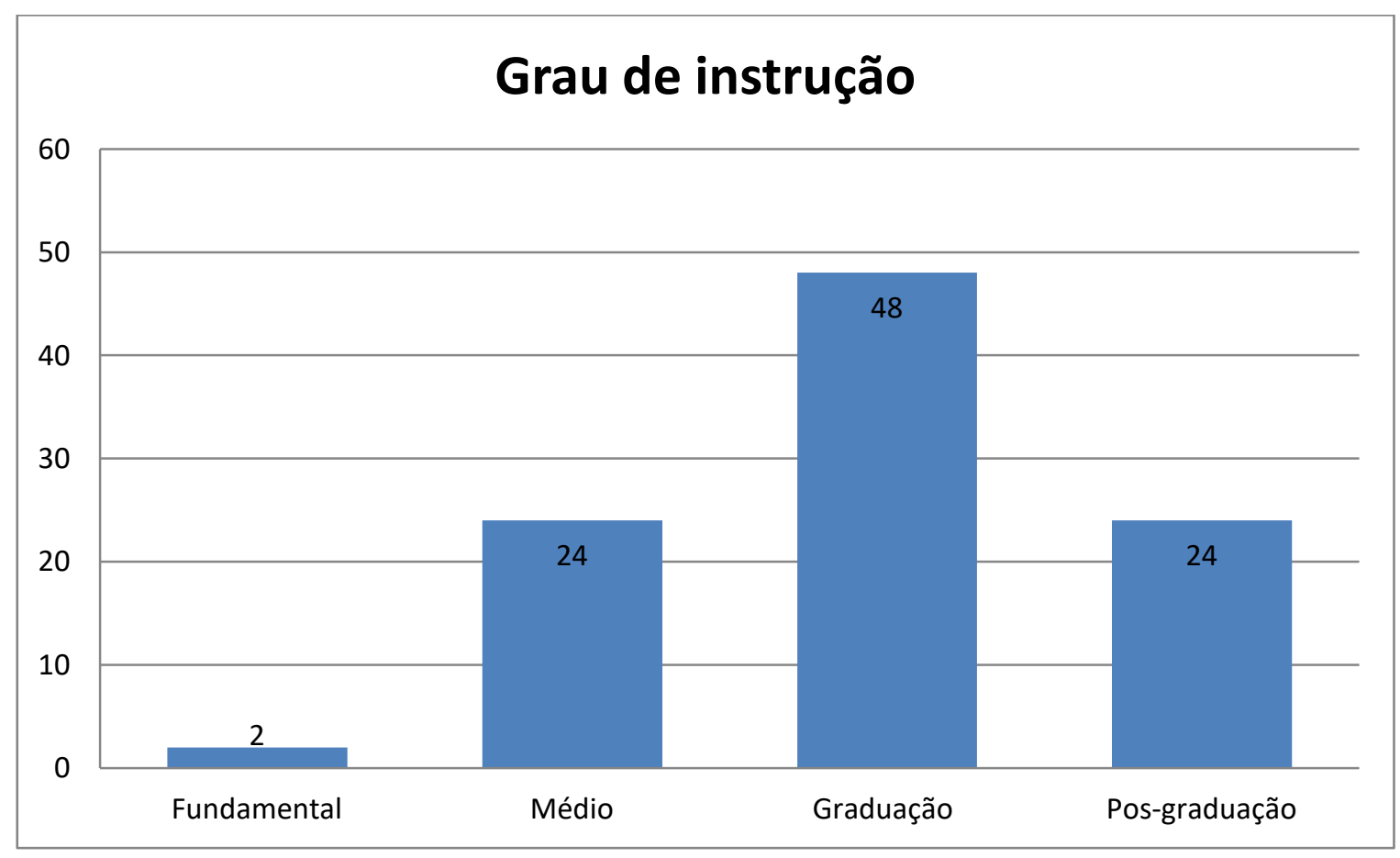


Figura 8 - Renda mensal

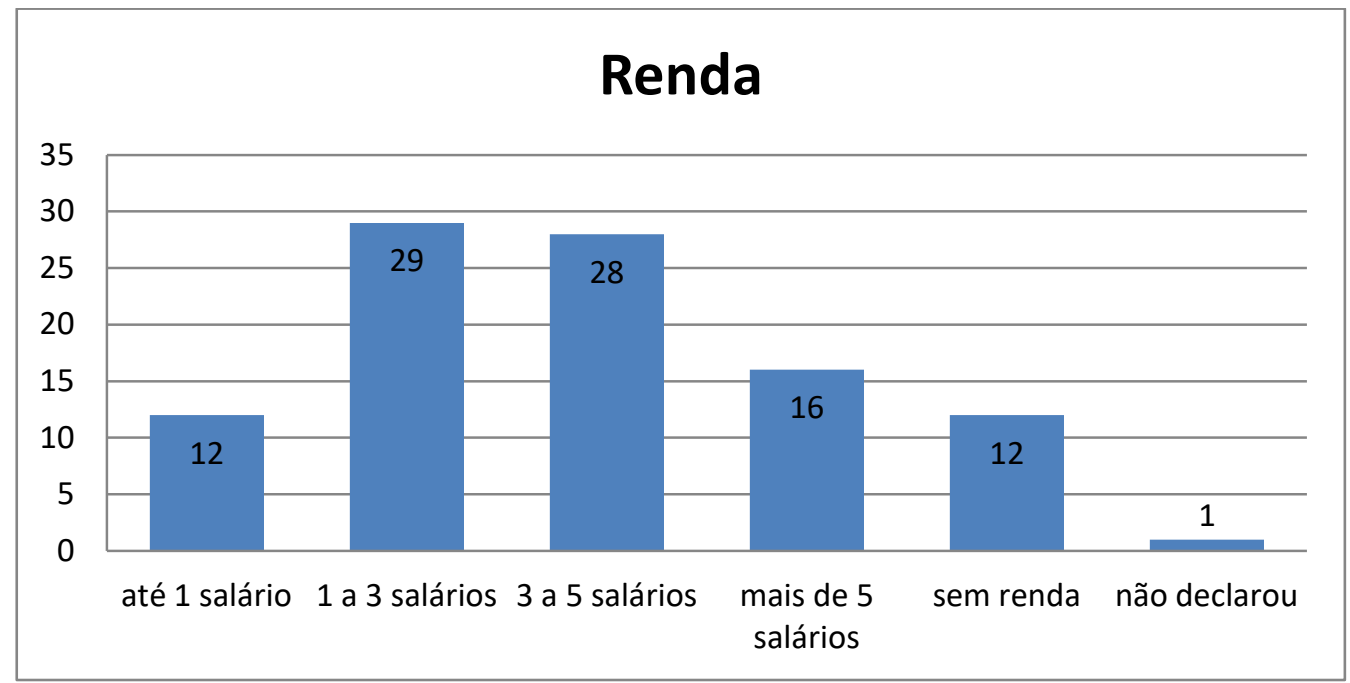

A maioria dos entrevistados (Figura 9) marcou a opção "outro" (54 pessoas), o que sugere uma visitação esporádica e sem regularidade. Do total, 37 pessoas assinalaram visitas anuais, enquanto apenas 7 visitantes frequentam a área semanalmente (3\%) e mensalmente (4\%).

Figura 9 - Frequência das visitas dos entrevistados

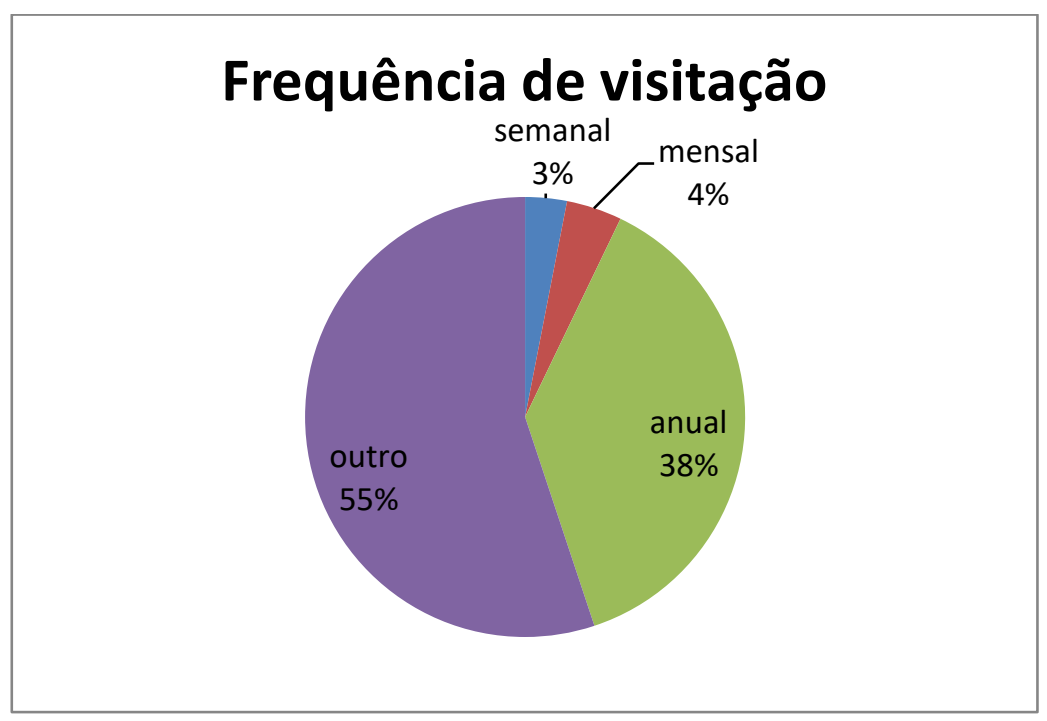

A primavera e o verão foram assinalados como estações preferenciais de visita, respectivamente 36 e 24 usuários (Figura 10). Outros 24 declararam que frequentam a trilha o ano inteiro, o que pode estar associado com a proximidade do local. Enquanto isso, um número menor visita no outono e inverno, respectivamente 2 e 4 usuários $(6,1 \%)$ 
Figura 10 - Período preferencial de visitação

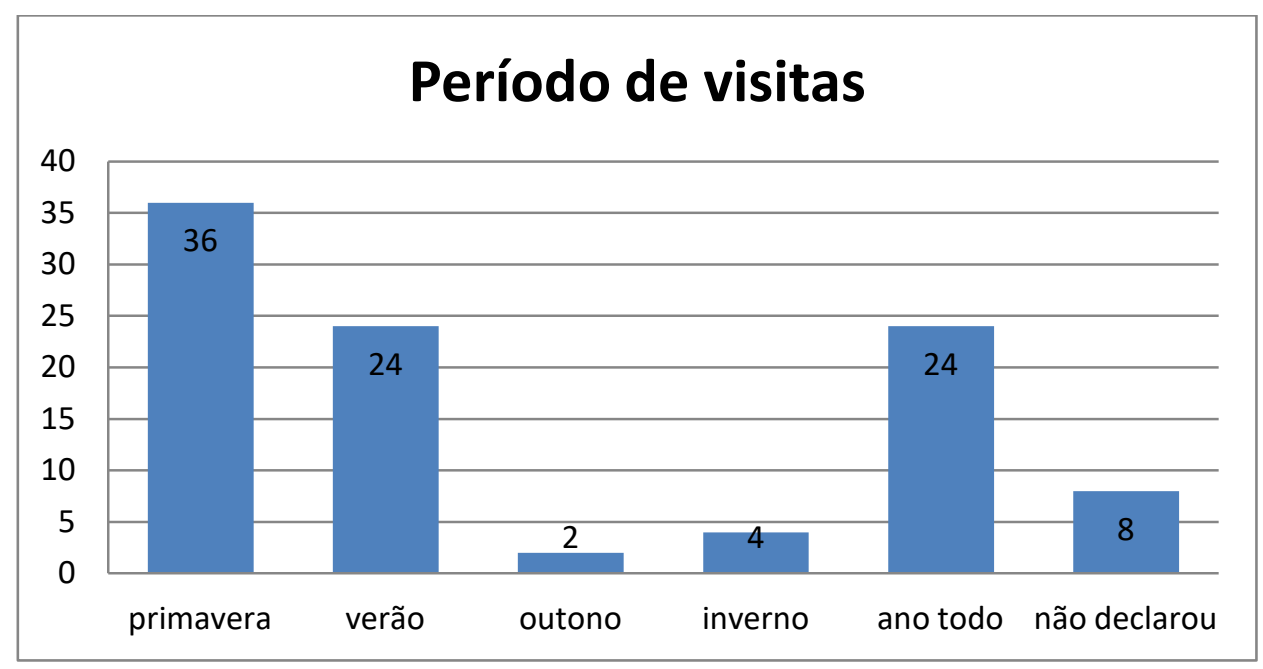

A grande maioria assinalou que estava frequentando a área pela primeira vez $(69,4 \%)$. Esse dado pode ter relação com outro tópico do questionário "frequência das visitas" no qual 54 pessoas marcaram como "outro" nas opções propostas. Nas demais opções os números oscilaram entre 6 (4 vezes) e 8 ( 2 e 5 vezes) que frequentam a área de forma mais regular (Figura 11).

Figura 11 - Quantidade de visitas

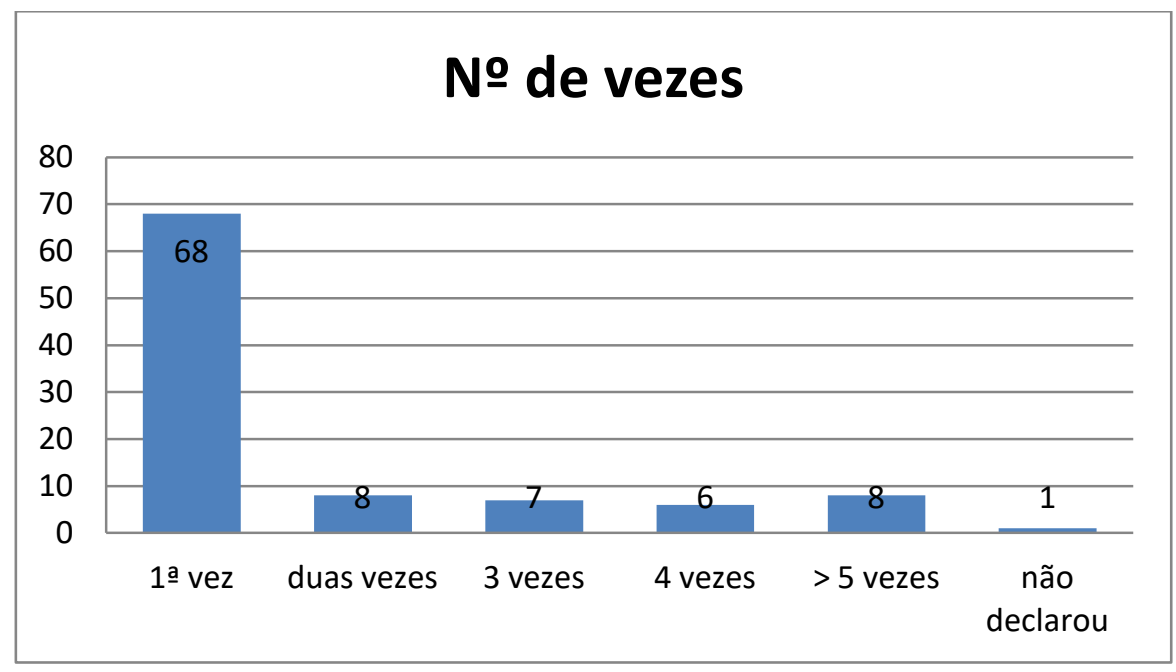

Sobre os interesses de visitação, as respostas poderiam contemplar diversas opções não excludentes entre si, tais como os banhos de cachoeira, caminhadas, contemplação, realização de piqueniques, fotografias, etc. A procura exclusiva pelos banhos de cachoeira foi considerada como principal objetivo para a maioria dos entrevistados $(23,5 \%)$, seguido pela combinação com 
as caminhadas e contemplação da natureza (13,3\%). As demais respostas não deixaram de assinalar as cachoeiras como objetivo integrado a outras finalidades.

A maioria dos visitantes (34) declarou que faz a trilha acompanhada de apenas uma pessoa (34,7\%), 19 usuários informaram percorrer a trilha com 3 pessoas $(19,4 \%)$. Dez visitantes informaram fazer a trilha com mais de cinco pessoas $(10,2 \%)$.

Sobre o tipo de hospedagem, a maioria $(36,7 \%)$ revelou que se hospeda em pousadas, seguido pelos campings $(30,6 \%)$. Vinte e cinco entrevistados $(25,5 \%)$ revelaram não ter se hospedado em nenhuma das opções sugeridas, o que indica a ocorrência de visitas com menos de 24 horas de duração. Apenas seis respostas $(6,1 \%)$ foram de usuários de segunda residência e uma única resposta de morador local.

A grande maioria $(62,2 \%)$ informou que conheceu a trilha por meio de amigos; seis por meio de familiares; cinco através das redes sociais e outros seis por meio de pesquisa de sites na internet. Quatorze visitantes tomaram conhecimento através de outras fontes.

O Quadro 1 destaca a origem dos entrevistados segundo as regiões do estado do Rio de Janeiro. A maioria dos visitantes declarou sua origem em municípios da Região Metropolitana do RJ, totalizando 58 pessoas $(58,8 \%)$. A maior parte veio da cidade do Rio de Janeiro (36), São Gonçalo (10), Niterói (6) e de vários municípios da baixada fluminense, como Duque de Caxias, Nilópolis, Nova Iguaçú, São João de Meriti e Queimados. A Região das Baixadas Litorâneas veio em segundo lugar com 22 visitantes originários dos municípios de Araruama (6), São Pedro da Aldeia (5), Cabo Frio (4), Rio das Ostras (3), Casemiro de Abreu (2), Saquarema e Rio Bonito, ambos com apenas 1 .

A amostragem também revelou dados interessantes sobre a presença de visitantes de outros estados como o Espírito Santo (Iúna e Vitória), das capitais de São Paulo e Bahia, além do Acre (Rio Branco).

Quadro 1 - Regiões de origem dos entrevistados

\begin{tabular}{|c|c|c|}
\hline Região & Número & $\mathbf{\%}$ \\
\hline RM do Rio de Janeiro & 58 & 58,2 \\
\hline Região das Baixadas Litorâneas & 22 & 22,4 \\
\hline Região Norte Fluminense & 8 & 8,2 \\
\hline Região Serrana & 2 & 2,0 \\
\hline Região da Costa Verde & 1 & 1,0 \\
\hline Outros Estados & 7 & 7,1 \\
\hline
\end{tabular}

No tocante às perguntas abertas, todos os entrevistados assinalaram "sim" sobre a importância de se preservar a área que está inserida a Trilha do Peito do Pombo. Entretanto, quando questionados sobre os motivos, 38 pessoas $(38,8 \%)$ não responderam e as outras 60, em sua grande maioria, forneceram respostas gerais baseadas nos ideais de preservação e 
conservação da natureza/meio ambiente. Alguns manifestaram preocupação com as gerações futuras entre outros aspectos. Quando buscamos opiniões para melhoria da visitação, 76 entrevistados $(77,5 \%)$ não deram sugestões e os outros 22 , em sua maioria, sugeriram mais placas de sinalizações de todos os tipos na trilha entre outras sugestões.

\section{CONCLUSÕES}

Os resultados obtidos permitiram estabelecer uma visão geral sobre o uso público e o perfil dos visitantes da trilha do Peito do Pombo. A área desperta interesse para um contingente de pessoas que busca nas cachoeiras e piscinas naturais a apreciação, o lazer e a recreação. $\mathrm{O}$ trecho estudado é curto com pequenos declives e bastante acessível para a maioria das pessoas sem a necessidade e guias e aparatos de segurança sofisticados. $\mathrm{Na}$ amostragem observou-se que os visitantes vêm de várias regiões do estado do Rio de Janeiro, além de outros estados do Brasil. A comunicação pessoal foi declarada como principal meio de difusão do conhecimento e da visita ao local. Pousadas e campings, quase na mesma proporção, abrigam os visitantes, mas cerca de $1 / 4$ dos entrevistados não permanecem por mais de 24 horas no local. Os meses mais quentes são, naturalmente, mais atrativos à visitação de pessoas com predominância de nível superior e renda entre 1 e 5 salários mínimos. A grande maioria estava visitando a área pela primeira vez em duplas e em grupos de 3 a 5 pessoas. Ampla maioria não quis, ou não soube, fornecer sugestões de melhorias, enquanto alguns mencionaram a necessidade de placas de sinalização.

Verificou-se que a situação do piso, em geral, é boa e não há grandes declives na maior parte da trilha, o que favorece a visitação ao primeiro atrativo da trilha, o poço do Escorrega. Porém, observa-se a necessidade de estruturas de manejo, como a instalação de guarda-corpo, por oferecer risco de queda ao visitante em alguns pontos onde os usuários caminham muito próximo do talude inferior, que se apresenta muito íngreme. Vale ressaltar que existem algumas partes da trilha que demandam maior atenção em relação às medidas de manejo e adequação. Em alguns pontos observou-se presença de lixo, pichações nas placas e na vegetação, feições erosivas em seu leito, indicando a necessidade de recuperação e de adoção de técnicas de manejo, incorporação de matéria orgânica no leito e alteração no traçado da trilha onde há erosão da borda. A necessidade de adequação da trilha para minimização dos impactos negativos, como processos erosivos, e segurança do visitante, pode ser reforçada a partir da análise do perfil do visitante no qual foi possível levantar informações pertinentes sobre os usos da trilha.

Propõe-se que na trilha do Peito do Pombo sejam instaladas placas no início do seu percurso com informações de suas características gerais, como extensão, principais declives, tempo de percurso aos principais atrativos e da trilha como um todo, grau de dificuldade, entre outros. Estas informações irão contribuir de forma positiva na segurança e experiência do usuário. 


\section{REFERÊNCIAS BIBLIOGRÁFICAS}

ANDRADE, M.A; BRITO, I.A; FIGUEIREDO, M.A; ROCHA, C.T.V; TAKEUCHI, R.C; Compactação do solo como indicador pedogeomorfológico para erosão em trilhas de unidades de conservação: estudo de caso no Parque Nacional da Serra do Cipó, MG.Revista de Geografia. Recife: UFPE - DCG/NAPA, v. especial VIII SINAGEO, n. 3, Set. 2010

ANDRADE, W. J. Implantação e manejo de trilhas. In. Mitraud, S. (Org.). Manual de Ecoturismo de Base Comunitária: ferramentas para um planejamento responsável. Brasília: WWF Brasil, 2003. p. 247-259.

BRASIL. LEI No 9.985, de 18 de julho de 2000. Institui o Sistema Nacional de Unidades de Conservação da Natureza (SNUC). Brasília: IBAMA, Diretoria de Ecossistemas, 2002.

COSTA, V. C. Propostas de Manejo e Planejamento Ambiental de Trilhas Ecoturísticas: Um Estudo no Maciço da Pedra Branca - Município do Rio de Janeiro (RJ). Tese (Doutorado em Geografia) - Instituto de Geociências, Universidade Federal do Rio de Janeiro, Rio de Janeiro, 2006.

COVA, B. F. G; PIMENTEL, D. S. Mapeamento das trilhas do Parque Estadual da Serra da Tiririca (RJ): Planejamento para a gestão do uso público. Uso Público em Unidades de Conservação, Niterói, v.1, n.1, p.48-59, 2013. Disponível em <http://www.uff.br/usopublico>. Acesso em 15/01/2019.

GASPAR, N. M. Transformações no meio rural, atividades turísticas e medidas de proteção ambiental: o caso do Sana. Dissertação de mestrado. Rio de Janeiro: UFRJ/IFCS, 2003.

GIL, A. C. Como elaborar projetos de pesquisa. São Paulo: Atlas, 1989.

INSTITUTO FLORESTAL/SP. Manejo de trilhas: um manual para gestores - IF Série. Registros. Secretaria de Meio Ambiente - São Paulo, n.35. São Paulo, 2008.

KROEFF, L. L. Contribuição metodológica ao planejamento de trilhas ecoturísticas no Parque Nacional da Serra dos Órgãos (PARNASO), RJ. Dissertação (Mestrado em Geografia) - Instituto de Geociências, Universidade Federal do Rio de Janeiro, Rio de Janeiro, 2010.

LABES, E. M. Questionário: do planejamento a aplicação na pesquisa. Chapecó: Grifos, 1998.

MAGRO, T. C. Impactos do Uso público em uma trilha no planalto do Parque Nacional do Itatiaia - Tese (Doutorado em Ciências da Engenharia Ambiental) - Escola de Engenharia de São Carlos, Universidade de São Paulo, São Paulo, 1999.

MELLO, F. A. P. Ordenamento da malha de trilhas como subsídio ao zoneamento ecoturístico e manejo da visitação no Parque Natural Municipal de Nova Iguaçu - RJ. Dissertação (Mestrado em Geografia) - Instituto de Geografia, Universidade do Estado do Rio de Janeiro, Rio de Janeiro, 2008. 
MINISTÉRIO DO MEIO AMBIENTE. Diagnóstico da visitação em parques nacionais e estaduais. Brasília: Ministério do Meio Ambiente. Secretaria de Biodiversidade e Florestas, 2005 .

PREFEITURA MUNICIPAL DE MACAÉ (PMM). Área de Proteção Ambiental de Macaé, RJ. Plano de Manejo da APA do Sana 2003. Disponível em: < http://www.macae.rj.gov.br/midia/conteudo/arquivos/1355215772.pdf > Acesso em 25/01/2019

RANGEL, L. A. Avaliação da trilha Sahy-Rubião no Parque Estadual Cunhambebe em Mangaratiba (RJ) 2016. Monografia (Especialização em Análise Ambiental e Gestão do Território) - Escola Nacional de Ciências Estatísticas, Instituto Brasileiro de Geografia e Estatística, Rio de Janeiro, 2016.

RANGEL, L. A.; BOTELHO, R. G. M. Análise ambiental da trilha Sahy-Rubião no parque estadual Cunhambebe em Mangaratiba $(R J)$ por meio de um protocolo de avaliação rápida. Geo UERJ, Rio de Janeiro, n. 30, p. 391-418, 2017.

RANGEL, L. A; MARTINS, M. B; GUERRA, A. J. T. Impactos ambientais causados pela utilização de trilhas na Reserva Ecológica da Joatinga, Paraty, RJ. In: Anais Uso Público em Unidades de Conservação, Niterói, v.1, n.3, p.55-65, 2013. Disponível em < http://www.periodicos.uff.br/uso_publico/article/view/28715/16658>. Acesso em 15/01/2019.

SEABRA, L. S. Monitoramento participativo do turismo desejável - Uma proposta metodológica para os estudos de capacidade de suporte turístico no Sana - Macaé - RJ. Tese - Universidade Federal do Rio de Janeiro - Programa de Pós Graduação em Geografia, 2005.

SILVA, A. O. da; CASTRO, A. O. C. de. Avaliação dos impactos de uso público na trilha ecológica da praia do Perigoso - Parque Natural de Grumari, RJ. In: Anais Uso Público em Unidades de Conservação, Niterói, v.1, n.5, p.01-12, 2015. Disponível em:< http://www.periodicos.uff.br/uso_publico/article/view/28757/16685> Acesso em 25/01/2019.

TAKAHASHI, L. Y. Caracterização dos visitantes, suas preferências e percepções e avaliação dos impactos da visitação pública em duas unidades de conservação do Estado do Paraná. Tese (Doutorado em Engenharia Florestal) - Universidade Federal do Paraná, Curitiba, 1998. 